\title{
Analysis on the Innovation of Financial Management Thinking of Public Institutions Under the Background of Big Data
}

\author{
Wenwen Qian*
}

\author{
China Institute of Geo-Environment Monitoring \\ *Corresponding author. Email: 162001578@qq.com
}

\begin{abstract}
"Big data" has brought about the innovation in social management concepts, and begun to challenge traditional financial management models. In public institutions, the level of financial management informatization is generally not high, and the management concept and method are relatively conservative. Only by participating in the reform in a timely manner will they keep up with the pace of development of the times and satisfy the needs of national governance. The author analyzes the necessity of reforming the financial management thinking of public institutions and puts forward corresponding suggestions.
\end{abstract}

Keywords: Big data, Public institution, Financial management informatization.

\section{INTRODUCTION}

With the increasing maturity of information technology, "big data" has become a hot word at this moment, and it has also brought the innovation in social management concepts. Along with this, the trend of financial management informatization and accounting intelligence has become increasingly evident, which has begun to challenge the traditional financial management model. As a special social organization in China, although public institutions are not in the frontier in this change, the author still believes that it is necessary to take precautions to update the concept and establish the big data thinking of financial management in a timely manner so as to better respond to environmental changes and adapt to the development of the times.

\section{NECESSITY OF INNOVATION OF FINANCIAL MANAGEMENT THINKING OF PUBLIC INSTITUTIONS UNDER THE BACKGROUND OF BIG DATA}

\subsection{To Adapt to the Development of the Times Better}

At present, the level of financial management informatization in public institutions in China is generally not high, and the financial management model is still dominated by traditional methods. If the thinking is not innovated in time, it will be impossible to adapt to the development of the era of big data. The main problems are as follows:

2.1.1. Most public institutions have not yet established an organic and complete financial management information system.

Except the computerization of accounting processing, some other tasks in public institutions are manually processed; for public institutions with better situation, an online reimbursement system is established based on the former and the reimbursement review is incorporated into the information system; moreover, in some public institutions, a project library management module has been established on the basis of the former two, which builds the bridge between the budget management and daily reimbursement management by means of information technology. However, these information systems all have a flaw in common, that is, the lack of access to non-financial data and unstructured data, such as contract information, performance data and certification during project execution. 


\subsubsection{Financial supervision is still dominated by} traditional paper-based bill review and supervision, lacking in the emphasis on the information other than bills

Also, the overall ability of risk prevention and control is relatively weak. Although many publish institutions have achieved the online reimbursement approval with the use of financial reimbursement system, the purpose of these institutions is to improve the reimbursement efficiency through remote approval, but not to achieve the transmission and collection of various data. The focus of financial reimbursement review is still dominated by traditional thinking, that is, whether the reimbursement bills are authentic and whether the reimbursement procedures are in compliance with requirements. However, there is still not enough attention to the information other than bills, such as the rationality of pricing, the final flow of funds, etc.

2.1.3. There is no enough emphasis paid to nonfinancial data, which cannot well reflect the ins and outs of the entire economic activity

The traditional financial reimbursement model pays less attention to non-financial data. In addition, considering the high cost for the storage of paper attachments, non-financial data attachments are not required or it is only necessary to provide some key pages in the reimbursement, and thus it is impossible to show the ins and outs of the entire economic activity. These non-financial data mainly include: decision-making approval documents or meeting minutes, some important records in the project execution process, phased results acceptance data, satisfaction questionnaire, etc.

\subsection{To Satisfy the Needs of National Governance}

Most of the funding of public institutions comes from fiscal funds, and the legality and performance of the use of funds are directly related to the national governance capability. As an important part of national governance, auditing has been at the forefront of social changes. The change in government audit thinking and work process brought about by the big data revolution requires that the audited public institutions must update relevant concepts in a timely manner in order to better cooperate with the needs of audit, and better prevent and control financial management risks in public institutions.

\subsection{To Adapt to the Dynamic Monitoring Requirements of Financial Departments}

With the establishment and continuous extension of the dynamic monitoring mechanism for the centralized payment of the national treasury, the daily economic activity of public institutions have been included in the dynamic and tracking monitoring scope of financial departments. It is necessary for public institutions to change the traditional financial management model and transform from the thinking mode dominated by the standardization review of bills to the substantive review of capital flow, etc., so as to discover problems in a timely manner and better adapt to the dynamic monitoring requirements of financial departments.

\section{ESTABLISHMENT OF BIG DATA THINKING IN THE FINANCIAL MANAGEMENT OF PUBLIC INSTITUTIONS}

Big data management is the requirement of the times and the need of national governance. So how should public institutions establish the big data thinking in the financial management? The author believes that we can proceed from the following three aspects.

\subsection{Planning in Stages Based on the Actual Situation}

The construction of financial management informatization should be promoted in stages based on the actual situation of different public institutions, so as to gradually improve the level of financial big data management.

There are many domestic public institutions in all walks of life, with different specific management requirements and informatization foundations. Therefore, it is necessary to formulate the financial management informatization construction plan in stages based on the actual situation of each public institution. The financial big data management platform that will be eventually established should be a complete and closed information management system from budget preparation, budget execution to budget performance evaluation. On this platform, we can evaluate whether the budgeting is scientific and reasonable based on objective and sufficient information and standards and monitor whether there are major risks in key nodes from budget execution, contract signing to contract execution. Also, it is possible to monitor whether the business transaction is true and the flow of funds is in compliance, and evaluate whether the performance objective is achieved. The results of the performance evaluation are used as an important constraint parameter in the next round of budgeting. In this process, some major link elements need to be focused: the analysis of business processes, the identification of key risks, the internalization of management systems, the implantation of control methods, the connection between management modules, the construction of the sharing platform of internal and external information of public institutions, and the generation and application of various decision-making data. 


\subsection{Strengthening the Special Training for Financial Staffs}

It is necessary to strengthen the special training for financial staffs in public institutions to enable them to establish the awareness of big data management and master the necessary knowledge and skills for big data management.

Compared with enterprises, the financial staff in public institutions is more traditional and conservative in terms of the management awareness and the use of management tools. "Big data" is like an ivory tower in the eyes of financial staff in many institutions, which is a very abstract concept. By participating in the big data management training customized by the institution, they can truly establish the concept of big data management and master certain knowledge and skills so as to pave the way for the coming of big data era of financial management.

\subsection{Strengthening the Publicity and Implementation of the Ideology for All Staff}

It is necessary to do a good job in the publicity and implementation of the ideology for all staff in public institutions, and in this way, the financial big data management thinking will be fully recognized by the staff of other departments, so that they will actively cooperate in the work.

Financial big data management is not the issue of a single department, but for the entire institution. The risk control and early warning in business processes, the establishment and operation of information sharing platforms, and the generation and utilization of various decision-making data all depend on the communication and cooperation between various departments. Only by the joint efforts and overall collaboration of various departments will the financial big data management platform really play its role.

\section{CONCLUSION}

The era of big data has come and only by reforming the thinking and strengthening the information construction will the financial management of public institutions adapt to the development of the times and satisfy the needs of national governance. This requires each institution to pay attention to the stage planning and continuous promotion of financial information construction based on its own actual situation and management needs. At the same time, it is also necessary to strengthen the professional training of financial staff and the publicity and implementation of the ideology of all staff in public institutions so that the concept of financial big data management will be truly implemented.

\section{REFERENCES}

[1] Jiang Honglan, Research on Government Audit Issues under the Background of Big Data, Communication of Finance and Accounting, 2019.7

[2] Peng Yihong, Strategy of Transition from Financial Accounting to Management Accounting under the Background of Big Data, Accounting Learning, 2019 (19)

[3] Chen Wei, Case Study of Big Data Audit Based on Visual Analysis Technology, The Chinese Certified Public Accountant, 2019 (6)

[4] Zhang Qinglong, Han Fei, He Jing, How Will the Financial Shared Services develop in the future Showing the Beauty of Cross-Industry Integration, Finance and Accounting, 2017 (16)

[5] Qin Rongsheng, Development Trend of Auditing and Accounting in the Era of Big Data, Friends of Accounting, 2014(32) 